\title{
Biology, bodies and human rights
}

\author{
Elaine Salo and Benita Moolman
}

\section{Conceptual rationale}

This issue of Agenda explores new developments in contemporary thinking and activism around the critical nexus of cultural meanings about biology and scientific biomedical processes, bodies and human rights in African feminist thinking. The intersections between biology, sex and bodies, and the social and cultural constructions of gender, and how these two arenas are mutually constitutive are important though under-examined in postapartheid and postcolonial contexts. Feminists have contested the limits and possibilities that patriarchal institutions such as the colonial and apartheid state have set for bodies and gender identities in the arenas of sexuality, affect, reproduction and childcare, that are female, black, homosexual, or are differently abled. Global scientific advances in reproductive technologies, sex change, and biomechanical engineering to expand the capacities of people living with disabilities have enhanced many lives. However these advances have also been utilised by states, religious, educational and health institutions to reproduce new forms of discrimination and exclusion of people considered to possess 'atypical bodies' that do not fit with the current or the ideal citizen. Barbara Brown's seminal paper (1987) examining the apartheid health services' provision of contraceptives and sterilisation to limit the fertility of black women in South Africa is a poignant reminder how supposedly neutral contraceptive technologies are marshalled for racist and xenophobic intents. Such abuses require feminists to examine the relationship between patriarchal power and biomedical and scientific knowledge about sexuality and reproduction. We have to ask who 'is allowed to exercise reproductive choice, assert sexual capacities and agency, and who is not, as well as what forms of reproductive or sexual agency, as well as significations of the body, emerge to realise these capacities in contexts of legal, religious, or biomedical constraints.

Even as social reproduction has removed barriers to reproduction, that was once seen as being women's primary biological role, new barriers to gender and sexual equality have arisen and are complicated by the contestation of the meanings of sex and the problematic policing of gender. Donna Haraway (1991) has argued that science and culture are often mutually constitutive. We contend that at least in the South African context, historically, culture and society have selectively utilised science to buttress beliefs and social policy in the field of human reproduction and sexuality. Social assumptions and cultural constructs about biology, bodies, capacities and rights inform our most sacred beliefs about whom we recognise as persons with sexual and reproductive agency. Such beliefs inform nation states' and citizens' beliefs about who has the right to reproduce, be sexually active, make decisions about sexuality and reproduction, or who can be responsible parents, raise the next generation of citizens, and form socially legitimate families. Indeed, such beliefs determine who has the right to the social goods that our society can offer, the right to protection of life, the right to decision-making about their reproductive capacities, whether, when and how to bear children, whom to love, to desire, how to clothe our bodies and to claim rights to particular identities. These beliefs also inspire our beliefs about who is considered worthy of the dignity of being considered fully human.

Ever since Linnaeus the $18^{\text {th }}$ century Swedish scientist conducted scientific examinations and classification of indigenous Khoe women's genitalia and set the stage for the Musée De La 
Homme's display of Sara Baartman's labia, scientific discourse has played a major role in the definition of 'deviant bodies', othered, subjected to the gaze of, and defined by its civilising discourse (Abrahams, 2004; Fausto Sterling, 2000). Such scientific discourse has been imbued with cultural understandings of who could be considered a member of the family of Man and accorded the dignity of human rights. In her analysis of Georges Cuvier's account of Sara Baartman, Ann Fausto Sterling (2000) notes that Cuvier's dissection of Bartmann (sic) was a natural expansion of European colonialist thinking that shaped scientific language and power. By the same token, Brandes (2004) notes that Baartman's restoration to South Africa informed the founding and restoration of dignity to a new postapartheid nation, as her feminine dignity, and her wholeness is restored. Consequently, the post-apartheid nation, re-instantiates a heterosexual binary as a key aspect of its national imagined community (McClintock, 1995; Brandes, 2004).

patriarchal control in the post-apartheid state is emerging, albeit unevenly, through official discourse and practices in the judicial, and health sectors in particular

So what does the newly post-apartheid nation make of its people who in their multiple diversities are differently abled or who cannot or will not support its biological and social reproduction in the expected conventional heterosexual ways? And what do ordinary members of the polity make of bodies whose contours, physical shapes, genital accoutrements and inner psychic states do not quite match the discourse of gender binaries or of heterosexuality? As Elaine Salo and Pumla Gqola (2006) and Elaine Salo (2010) have argued elsewhere, patriarchal control in the post-apartheid state is emerging, albeit unevenly, through official discourse and practices in the judicial, and health sectors in particular, especially in relation to gender based violence against lesbian women, the disparagement of rape victims' rights for the sake of political expediency ${ }^{1}$, and the state's denialist stance in HIV/AIDS in the 1990s. Such practices instantiate male authority, hetero-normative definitions of gender and sexuality, and hold sober implications for these persons' substantive claims to human rights in contemporary South Africa. The threat to these populations' rights to assert choice in relation to reproduction and sexuality is reinforced by dominant societal beliefs and norms about their capacities and abilities in these arenas.

Most South Africans and indeed most Africans on this continent do not accept or remain ambivalent that people with disabilities, children and the elderly have active sexualities or that Lesbian, Gay, Bi-sex, Transgender and Intersex (LGBTI) people should raise children, or form families. We stigmatise women who are unable to bear children, as well as those who choose to remain childless (Davids, 2008); often branding them as cursed or as witches. On the other hand, the very idea of disabled adults possessing sexuality, expressing sexual desire, reproducing, bearing children and parenting them remains a powerful taboo (Barry, 2005). Ordinary citizens remain ambivalent about the women and men who resort to adoptions across the boundaries of difference, as well as biomedical interventions such as Invitro Fertilisation (IVF), or the use of sperm donors to assist in the biological act of fertilisation, so that social parenting can ensue (Davids, 2008). Careful interrogation of such beliefs reflect how misplaced cultural values do marginalise ambivalent bodies and sexual agencies that don't conform to the norms of the biomedical establishments, often setting them up as future subjects of close regulation by the state and society.

The groundbreaking research, over a decade ago, by Anne Fausto Sterling in her book, Sexing the Body Gender Politics and the Construction of Sexuality (2000), provided physiological evidence to refute the idea that there are only two sexes. Sterling makes the argument that the subtle physiological gradations of human sexualities support the evidence of several sexes in the human population, instead of the binary twosome, male and female. Anthropologists such as Emily Martin $(1987 / 2001)$ have also argued that our understanding of the body and of biological processes is as informed by our cultural assumptions and biases as it is by assumptions about objectivity in research. In her publication, The Woman in the Body, she argues that the scientific method and discourse used in bio-medicine to describe and analyse biological processes, such as reproduction and sexuality, are shot through with western cultural constructs of sexuality and gender. Sylvia Tamale's (2011) theorising on sexuality in the African 
context gives further support to Martin's perspective. At the same time, a review of anthropological reports by Roscoe and Murray (2001), suggest that historically anthropological methods and anthropologists' heteronormative biases have entrenched the myth that homoeroticism and homosexuality are absent or incidental to African societies, when the opposite is true.

Taken together these biological scientists and cultural anthropologists' research has provided the opportunity to re-visit the disciplinary discourses and practices that examine the complex relationship between biology, bodies and human rights. They also allow us to examine in a careful manner the popular scientific claims that are so hegemonic in everyday assumptions and discourse about the body.

The issue builds on feminist analysis and research published in previous issues of Agenda 'Sexuality and body image' (No 63, 2005) and 'Sexuality in Africa' (No 62, 2004). These issues explored how the body acts as both the site and language through which positioning is negotiated, and the policing of bodies and the danger of homogenising discourses from the West in the interrogation and exploration of ideas. While acknowledging the transnational nature of women's oppression it also underlined the need for a freedom from prescriptions in exploring body politics and sexualities in Africa.

Submissions for this issue were invited to interrogate the underlying assumptions about the relationship between biology, gendered bodies and sexual and reproductive capacities that inform these powerfully held societal beliefs; how scientific evidence is marshalled, or elided to bolster such powerfully, commonly held beliefs, and how such information is passed on to successive generations of medical scientists through intellectual genealogies in science curricula. Such discourses may inform an emergent mode of bio-power in the postcolonial South. Foucault (1978) first used the concept bio-power as a heuristic device to describe how states used policies particularly in public health to regulate populations, determine heredity and to define citizens' phenotypic characteristics. We hoped that authors would inquire how human physiology inform state policies on marriage, social grants, housing, and inheritance; how persons who fall in the territory where biology and cultural ascriptions of sexuality, gender, and reproductive capacities are not neatly recursive, may negotiate life between these interstices and through the medical and state institutions where practices are informed by bodies and cultural identities 'that fit'.

This collection, therefore, sought to encourage authors to inquire about the relationship between biology, bodies, sex and gender that may inform a re-formulation of personhood and rights in contemporary African societies. The cumulative work presented here assist in charting some of the current debates about the relationship between biology, sex and gender and the social recognition or mis/recognition of persons, and their sexual and reproductive capacities.

\section{Biology, culture and governmentality}

Several contributions in this issues provide insights into the discursive power of the postapartheid South African state's emergent biopolitics and of the health and medical professions in eliding, enabling or 'correcting' persons' sexual, reproductive and subjective capacities because they live in the zones nuanced by unexpected complex overlays of biology and culture, beyond the ideals of recursive sexual dimorphism or physical and mental capacity. Such 'grey zones' present particular challenges to a new state where old and new forms of governmentality (Foucault, 1978) are emergent in the context of constitutional imperatives that embrace diversity and human rights. Such existential zones illustrate that the apparently recursive boundaries of these bio-cultural territories are fluid, and shifting, informing a considerable field of rich inquiry. We are asked to consider whether and how biology and biomedical opinions are assembled to enable or elide such persons' experiences, identities and capacities? Furthermore, whether and how forms of governmentality can expand to enable acceptance of human diversity as normative?

\section{the apparently recursive boundaries of these bio-cultural territories are fluid, and shifting, informing a considerable field of rich inquiry}

Nadzeya Husakouskaya in her Article asks us to consider how biomedical diagnostic systems overlay cultural discourses about acceptable queer sexuality to condemn intersex and transsexual persons to social death. Her Article focuses on the experiences of 
intersex and transsexual persons in their quest for recognition as social persons; citizens with rights. She maps out how transsexual and intersex black people in Gauteng journey between state medical institutions and LGBTI non-governmental organisations in their efforts to belong and find affirmation. She surfaces the power of psychiatric and medical discourse, as well as the hegemony of gay and lesbian identities' experiences in the LGBTI alliance that silences the experiences of trans and intersex people. Nadzeya uses the following quote as an illustration:

“He was like - 'this is going to take very long time cause we have to have several sessions and really going to why are you feeling like this and I need to prepare you for this now but you have to get naked cause I need to see'. I am like what the $f^{*}$... Why do you need to see? Like you are the psychologist! Like what is wrong with you?! He is like 'wow you'll find it very hard to find any[one] to work with you if you don't want to get undressed'. And I am like - 'no, dude, no!' (Laughing) So after that I was like - thank you very much, but I am going to leave now... and he was like - 'yeh, well, I think you are going to be back'. I left. It was ridiculous" (Interview with B., transman, 24 March 2013) (p 18).

\section{the dominant positivist paradigms which}

inform the practices and discourses of orthodox health sciences education have produced a tacit acceptance of racial hierarchies and of heteronormativity amongst professionals

Similarly Willene Holness maps out how otherwise loving caregivers and family members consistently violate the reproductive rights of women and girls with disabilities resulting in involuntary sterilisations. This situation persists because of the prevailing societal beliefs about these women's reproductive capacities and the sexual passivity associated with femininity. In such cases the rights of persons with disabilities are protected by international conventions, the constitution and associated policies. Holness interrogates the robustness of the policy environment as a possible supportive framework for these women's rights claims. Alexandra Müller and Sarah Crawford Browne in the Briefing in this issue examine the challenges in incorporating gender and sexuality education in the medical school and health sciences curricula. They argue that the dominant positivist paradigms which inform the practices and discourses of orthodox health sciences education have produced a tacit acceptance of racial hierarchies and of heteronormativity amongst professionals. They map out emergent transformations in curricula and research, based upon a transdisciplinary conversation between the social sciences and health sciences to inform a more substantive pedagogical project. Such transformative pedagogies claim a place in medical and public health curricula for critical feminist perspectives on gender. Such practices also support minorities' legitimate claims to agency and personhood by highlighting unsubstantiated moral or cultural discourse that inform the negation of their sexual and reproductive capacities. However, Müller and Crawford Browne indicate that the acceptance of such transdisciplinary conversations and pedagogical transformations require astute strategies, time and labour. Their Briefing raises questions about the entrenched linkages between the current knowledge/power nexus of health professionals' education in South Africa and health practice that fail to address the health needs of LGBTI people.

Renée Van Wiel's research interrogates biomedical professionals' role in reconfiguring breast cancer patients' embodied femininity, as she examines the rights of these women to refuse reconstructive surgery after mastectomies. Her findings which are based upon in-depth interviews, provide some insights into women's experiences of breast cancer. She questions the hyper-sexualisation of women's breasts, as her findings highlight breast cancer survivors' ability to reconstruct a positive feminine image despite the loss experienced during a mastectomy. She argues that women do not necessarily experience the cosmetic crisis that international research suggests is common in such surgery. She states that:

"Patients accepted mastectomy as a dimension of ensuring future health, and many rejected the opportunity to surgically reconstruct a prior, breasted body. Women perceived cancer as a threat to a healthy body, as far more serious than the threat posed to the gendered body by mastectomy" (p 62). 
The history of biomedical professionals' complicity in upholding racism in South Africa has unfolded during the trial of Dr Wouter Basson, a state physician who aided and abetted the assassination of anti-apartheid activists (/OLNews, 'Basson hearing resumes', 16 April 2013). The prominence of the Basson trial in South Africa conceals the work of health professionals who act to support women's, disabled people's and sexual minorities' sexual and reproductive rights. Many health professionals have played a key role in rolling back the worst practices of racism in the national health system. Makhosazana Xaba and Laetitia Rispel surface the historic role of nursing professionals in ensuring women's legal access to safe abortions in post-apartheid South Africa. Their Briefing provides an important recuperative intervention to the dominant historical narrative of nurses in South Africa. They utilise the concept 'positive deviance' as a heuristic device to unravel the hidden histories of nurses' mobilisation in support of the Choice on Termination of Pregnancy Act of 1996 (CTOP). Their empirically grounded research provides an important corrective to the dominant perception that nurses would prefer being conscientious objectors than participate in the provision of CTOP.

The Profile by Lizzie Lacey and the Perspective by Winni Ogana and Vivian Ojong shift the focus to cultural processes and values that draw upon and inform the sexual and gendered signification of women's bodies to configure and contest gendered and racial hierarchies. Lizzie Lacey examines the power of material wealth in men's gendered cultural claims to women's sexuality in South Sudan where women's abductions highlight the human rights of women in conflict, while Winnie Ogana and Vivien Ojong show how Zulu-speaking women lay claim to cultural values as they challenge dominant western ideals of feminine beauty. Their research interrogates how women's rights over sexuality and ownership of the body are shaped in relation to the fluid transformative contexts of civil war in the Sudan and the emergent postapartheid nation.

Nina Hoel examines women's engagement and interpretation of religious discourses in Muslim women's practice of their sexual autonomy. She shows that women are constrained in patriarchal interpretations of religion yet this is not finite, they find avenues for expression and a means of navigating their own sexual spaces within their intimate relationships and thus a reformulation of the 'sacred text'. Yet, micro practices of patriarchal power are so insidious in 'the everyday' that cultural and religious inscriptions are like an adhesive to social identities. As Hoel reminds us in her Article that

"while recognising some women's inventive embodied contestations, the current contours of an Islamic body politics markedly propose problematic discursive gendered norms rooted in sexual difference" (p 88).

Sarita Ranchod's Visual essay extends Ogana and Ojong's discussion about the meanings of beauty in relation to race in her pursuit of a personal aesthetic of Black womanhood. Her clay sculptural forms of black feminine nudes impel us to consider whether black feminine bodies can be equated with dominant ideals of beauty. She seeks to "shift perspectives, views and lenses towards celebrating Black beauty differently" ( $p$ 121) as her work in a journey of healing seeks to embrace women's rights and empowerment through creative expression, thus countering the degradation of the body in a society emerging from legal racism. These articles, taken together, ask us to consider the associations between nationalism, femininity and sexuality as these are informed by and impinge upon women's lives in postcolonial African societies.

We also include a report on the Agenda Feminist Dialogue on Women and Land and a critical reflection on South African women's dispossession of property through the 1913 Natives Land Act, a century after its promulgation, in this issue. Susan Nkomo's reflections provide a stark reminder of the connections between race, gender, territory and nationalism and the associated destruction of indigenous South Africans' communities through dispossession of land. She foregrounds the need to critique the master narrative in post-colonial discourse. Through the systematic process of excavating African women's voices and remembering of the colonial experiences she calls for the re-centring of women's perspectives in the feminist analysis of land dispossession. Finally, Sylvia Tamale unravels the interlinkages between sexuality, biomedical and legal and political institutions as she reflects upon her work in conversation with Elaine Salo. 


\section{Conclusion}

The collection of papers in the issue provides counter narratives to dominant forms of state and social regulation of bodies, sexuality and gender in African societies. These counter narratives disrupt normative bio-political and social discourses that serve to re-inscribe, and regulate sexual and reproductive bodies. The writers in this issue interrogate agency and disruption for different bodies and within institutions. They articulate the complex navigation of individual and collective agency in interstitial spaces.

South Africa is a newcomer to the more liberal world of democratic freedoms. Our notions of new rights and freedoms tend to be dominated by a consciousness of racial equality where the newly liberated citizen is the black, able bodied male. Contemporary judgments by our chief justice about the relative insignificance of child rape impels us to consider how bodies and identities are being ordered in a hierarchy of privilege and inferiority because of the perceptions of their personhood that rests upon the cultural meanings accorded to them. In considering the appeal of a man found guilty of raping a seven-year-old girl (the State vs Serekwane, 2005), Justice Mogoeng reduced the imposed sentence arguing that:

"One can safely assume that [the accused] must have been mindful of [the victim's] tender age and was thus so careful as not to injure her private parts, except accidentally, when he penetrated her. That would explain why the child was neither sad nor crying when she returned from the shop, notwithstanding the rape. In addition to the tender approach that would explain the absence of serious injuries and the absence of serious bleeding, he bought her silence and cooperation with Simba chips and R30" (Ilhaam Rawoot, 'Mogoeng's shocking child rape rulings', Mail and Guardian, 2 September 2011).

The chief justice's statement assists in setting up the normative hierarchies of personhood and citizenship in post-apartheid South Africa informed by the implicit values he accorded to gendered bodies or sexual identities. Feminists who seek to expand and protect the ideals of human rights in our new democracy, and who wish to imbue the Constitution with substantive material reality, need to interrogate these accretions of power and marginalisation by asking how these techniques of power/knowledge operate, and how they invoke biology to instantiate exclusive notions of personhood. Our special edition of Agenda presents new voices and research that contribute to this conversation. They ask us to continue to cultivate a feminist solidarity across regional boundaries and the authors inspire a feminist activism that expands the freedom to redefine the spaces we live in and to reclaim the pleasures of living within our bodies.

\section{Note}

1. The Zuma rape trial in recent history is an example of this situation (see Motsei, 2007).

\section{References}

Abrahams Y (2004) 'Gender and locating Sarah Baartman in the present' in AW Oliphant, P Delius \& L Meltzer (eds) Democracy X: Marking the Present, Re-Presenting the Past, Pretoria: University of South Africa,

Barry S (2005) Whole - A Trinity of Being, documentary film.

Brandes K (2004) 'Re-Considering Saartjie Baartman: Configurations of the 'Hottentot Venus' in contemporary cultural discourse, politics, and art' in $\mathrm{H}$ von Oldenburg \& A Sick (eds) Virtual Minds. Congress of Fictitious Figures, Bremen: Thealit Frauen.

Brown B (1987) 'Facing the 'black peril': the politics of population control in South Africa', in Journal of Southern African Studies, Special Issue: The Political Economy of Health in Southern Africa, 13, 2, $256-273$.

Davids B (2008) 'Somewhere there's a silver lining: Women's experiences of infertility on the Cape Flats', Unpublished thesis submitted in fulfillment of the M. Social Science degree, University of Cape Town.

Fausto Sterling A (2000) Sexing the Body Gender Politics and the Construction of Sexuality, New York: Basic Books.

Foucault M (1978) The History of Sexuality Vol 1: Introduction, New York: Random House.

IOLNEWS (2013) 'Basson's hearing resumes', 16 April, http://www.iol.co.za/news/south-africa/ basson-s-hearing-resumes-1.1500710, accessed 29 Nov 2013.

Harraway D (1991) Simians, Cyborgs and Women, Routledge: New York.

Martin E (2001) The Woman in the Body: A Cultural Analysis of Reproduction (1st edition 1987), Boston: Beacon Press.

McClintock A (1995) Imperial Leather: Race, Gender and Sexuality in the Colonial Context, New York: Routledge.

Motsei M (2007) The Kanga and the Kangaroo Court Reflections on the Rape Trial of Jacob Zuma, Jacana: Cape Town.

Rawoot I (2011) 'Mogoeng's shocking child rape rulings', Mail and Guardian, 2 September, http://mg. 
co.za/article/2011-09-02-mogoengs-shockingchild-rape-rulings, accessed, 3 December 2013.

Roscoe SO \& Murray W (2001) Boy-Wives and FemaleHusbands, Studies in African-American Sexualities, New York: Palgrave Macmillan.

Salo E (2010) 'South African feminisms. A coming of age?' in A Basu (ed) Women's Movements in the
Global Era - The Power of Local Feminisms, Boulder: Westview Press.

Salo E \& P Gqola (2006) 'Editorial', in Feminist Africa, 6, Subaltern Sexualities, 1-6.

Tamale S (2011) 'Researching and theorising sexualities in Africa' in S Tamale (ed) African Sexualities: A Reader, Dakar: Pambazuka Press.

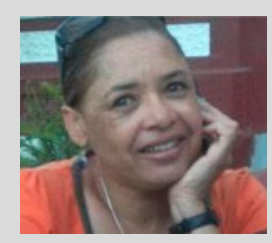

ELAINE SALO is associate professor in Social Anthropology and the director of the Institute for Women's and Gender Studies at the University of Pretoria, South Africa. Her research interests include the women's and gender social movements in southern Africa, gender and transformation in the higher education environment as well as gendered identities and sexuality in urban space. Elaine has been active in establishing women's and gender studies as an academic field in Southern Africa and on the continent for the past 20 years. In addition she has worked with civil society and the state to realise gender justice in South Africa. She has done policy related research on gender mainstreaming for various sectors of the South African state as well as for the University of Zambia, Lusaka Zambia. Email: Elaine.Salo@up.ac.za; Saloelaine@gmail.com

BENITA MOOLMAN is a Research Specialist in the Human and Social Development Unit. She holds an M (Phil) in Women and Gender Studies at the University of the Western Cape and obtained a PhD in Feminist Geography from the University of California, Davis in the United States. Before joining the HSRC in December 2011, she was Project Coordinator at Rape Crisis Cape Town. She has also worked in the areas/organisations of gender violence, sexualities, and community development. Her areas of research interest include: intersectionality of race, class, sexuality and gender, African, urban and sexual spaces, gender violence and narrative methodologies. Her most recent work is entitled, 'Rethinking "Masculinities in Transition" in South Africa. Considering the intersectionality of race, class, sexuality with gender' published in African Identities, 11, 1 (2013). Email: bmoolman@hsrc.ac.za 